\title{
CYP4F18-Deficient Neutrophils Exhibit Increased Chemotaxis to Complement Component C5a
}

\author{
Rachel Vaivoda, ${ }^{1}$ Christine Vaine, ${ }^{1}$ Cassandra Boerstler, ${ }^{2}$ \\ Kristy Galloway, ${ }^{2}$ and Peter Christmas ${ }^{1,2}$ \\ ${ }^{1}$ Nephrology Division, Department of Medicine, Massachusetts General Hospital, Charlestown, MA 02129, USA \\ ${ }^{2}$ Department of Biology, Radford University, Radford, VA 24142, USA \\ Correspondence should be addressed to Peter Christmas; pchristma2@radford.edu
}

Received 16 July 2015; Revised 27 September 2015; Accepted 18 October 2015

Academic Editor: Carlos Rosales

Copyright (C) 2015 Rachel Vaivoda et al. This is an open access article distributed under the Creative Commons Attribution License, which permits unrestricted use, distribution, and reproduction in any medium, provided the original work is properly cited.

CYP4Fs were first identified as enzymes that catalyze hydroxylation of leukotriene $\mathrm{B}_{4}\left(\mathrm{LTB}_{4}\right)$. CYP4F18 has an unusual expression in neutrophils and was predicted to play a role in regulating $\mathrm{LTB}_{4}$-dependent inflammation. We compared chemotaxis of wildtype and Cyp4f18 knockout neutrophils using an in vitro assay. There was no significant difference in the chemotactic response to $\mathrm{LTB}_{4}$, but the response to complement component C5a increased 1.9-2.25-fold in knockout cells compared to wild-type $(P<$ 0.01). This increase was still observed when neutrophils were treated with inhibitors of eicosanoid synthesis. There were no changes in expression of other CYP4 enzymes in knockout neutrophils that might compensate for loss of CYP4F18 or lead to differences in activity. A mouse model of dextran sodium sulfate colitis was used to investigate the consequences of increased C5a-dependent chemotaxis in vivo, but there was no significant difference in weight loss, disease activity, or colonic tissue myeloperoxidase between wild-type and Cyp4f18 knockout mice. This study demonstrates the limitations of inferring CYP4F function based on an ability to use $\mathrm{LTB}_{4}$ as a substrate, points to expanding roles for CYP4F enzymes in immune regulation, and underscores the in vivo challenges of CYP knockout studies.

\section{Introduction}

CYP4Fs are a family of cytochrome P450 (CYP) enzymes that were first identified for their ability to catalyze end-chain hydroxylation and inactivation of leukotriene $\mathrm{B}_{4}\left(\mathrm{LTB}_{4}\right)$ [1]. The potency of $\mathrm{LTB}_{4}$ as an inflammatory mediator in normal immune responses and pathologies is well established. $\mathrm{LTB}_{4}$ is generated by the 5-lipoxygenase pathway of arachidonic acid metabolism and is implicated in the progression of diverse immune disorders such as inflammatory bowel disease, ischemia-reperfusion injury (IRI), arthritis, and asthma $[2,3]$. Therefore, CYP4Fs are predicted to play a significant role in the regulation of inflammation and prevention of disease. There is growing evidence to support this possibility. CYP-dependent $\mathrm{LTB}_{4}$ hydroxylase activity limits neuroinflammation in mouse models [4] and might contribute to the beneficial effects of retinoids in the treatment of inflammatory skin diseases $[5,6]$. Neutrophils and colonic mucosa from patients with inflammatory bowel disease have reduced $\mathrm{LTB}_{4}$ hydroxylase activity $[7,8]$, and genetic association studies link variants of the CYP4F2 and CYP4F3 genes with celiac disease and Crohn's disease $[9,10]$.

Human neutrophils have been used for detailed studies of CYP-dependent $\mathrm{LTB}_{4}$ metabolism: hydroxylation at the terminal $(\omega)$ position generates 20 -hydroxy $\mathrm{LTB}_{4}$, which is subsequently converted to the inactive metabolite 20-carboxy $\mathrm{LTB}_{4}$ [11]. This is the major pathway for the inactivation of $\mathrm{LTB}_{4}$ in human neutrophils $[12,13]$. The enzyme responsible for the initial $\omega$-hydroxylation step was identified as CYP4F3 $[14,15]$, and subsequently we demonstrated that this enzyme is an alternative splice form of the CYP4F3 gene designated as CYP4F3A [16]. A second splice form, CYP4F3B, has lower activity for $\mathrm{LTB}_{4}$ and is expressed in different locations such as liver and kidney [17]. The unusual localization and high expression of CYP4F3A in human neutrophils, and its high activity for $\mathrm{LTB}_{4}$ as a substrate, suggest that inactivation of $\mathrm{LTB}_{4}$ is a specialized function of the enzyme. There is 
evidence for temporal expression of CYP4Fs consistent with the resolution phase of inflammation in some experimental models [18], but expression of CYP4F3A in neutrophils does not fit this time frame. Neutrophils are short-lived cells associated with the early stages of inflammation, and CYP4F3A is expressed at a high constitutive level both before and during inflammatory recruitment of the cells [19]. It is possible that $\mathrm{LTB}_{4}$ inactivation functions to restrain neutrophil infiltration and prevent excessive inflammation. An alternative possibility is that $\mathrm{LTB}_{4}$ inactivation plays a role in neutrophil polarization, which is required to maintain normal chemotaxis [20].

We developed mouse models to better understand the role of CYP4Fs in neutrophil-dependent inflammation. We identified the CYP4F18 enzyme as the mouse homologue of CYP4F3A [21] and generated targeted deletions in the Cyp4f18 gene. Neutrophils from Cyp4f18 knockout mice exhibit a null phenotype for end-chain hydroxylation of $\mathrm{LTB}_{4}$ [22]. However, there are significant differences between mice and humans. The Cyp4fi8 gene is not alternatively spliced and generates a single enzyme that is homologous to CYP4F3A in sequence, localization to neutrophils, and high activity for $\mathrm{LTB}_{4}$. The products of end-chain hydroxylation by CYP4F18 are 19-hydroxy $\mathrm{LTB}_{4}$, and to a lesser extent 18-hydroxy $\mathrm{LTB}_{4}$, not 20-hydroxy $\mathrm{LTB}_{4}[21,22]$. It is not known whether $\omega-1$ and $\omega$-2 hydroxylation of $\mathrm{LTB}_{4}$ represents an efficient inactivation pathway. Furthermore, mouse neutrophils have an alternative pathway of $\mathrm{LTB}_{4}$ metabolism that involves a 12-hydroxydehydrogenase. Knockout of Cyp4f18 does not impact neutrophil infiltration into kidney tissue and disease pathology in a mouse model of renal IRI [22], although inhibition of $\mathrm{LTB}_{4}$ synthesis does have observable effects in this model [23]. It appears that CYP4F18 is redundant for $\mathrm{LTB}_{4}$ inactivation in mouse neutrophils, and we speculated that it might have an alternative function in these cells.

Since the discovery of CYP4Fs, numerous in vitro substrates have been identified [1]. There are 7 members of the human CYP4F family including the two splice forms of CYP4F3 (4F2, 4F3A, 4F3B, 4F8, 4F11, 4F12, and 4F22) and 9 members of the mouse family (4F13, 4F14, 4F15, 4F16, 4F17, $4 \mathrm{~F} 18,4 \mathrm{~F} 37,4 \mathrm{~F} 39$, and 4F40). CYPs typically have broad and overlapping substrate specificity, and a single enzyme such as CYP4F3B might have the capacity to catalyze multiple reactions including inactivation of $\mathrm{LTB}_{4}$, generation of 20 hydroxyeicosatetraenoic acid (20-HETE), and modification of fatty acid epoxides $[1,24]$. This suggests potentially diverse and prominent roles for CYP4Fs in immune regulation but creates a challenge for the identification of physiologically relevant substrates [25]. It is possible that CYP4Fs have different functions in different tissue locations, and new experimental systems will be required to determine the significance of particular reactions and disentangle the effects of multiple CYP4Fs. CYP4F18 is the only CYP4F family member expressed at high levels in mouse neutrophils, so Cyp4f18 knockout mice provide a novel system to dissect diversity of function. In this report we demonstrate that neutrophils from Cyp4f18 knockout mice show increased chemotaxis to complement component C5a that is independent of $\mathrm{LTB}_{4}$, an unexpected result that is not predicted by known CYP4F substrates.

\section{Materials and Methods}

2.1. Mice. Cyp4f18 knockout (-/-) mice were generated in a C57BL/6 background as previously reported [22] and are available at the Mutant Mouse Regional Resource Center (MMRRC) with the designation B6.129S4(Cg)Cyp4f18 ${ }^{\mathrm{tm} 1.1 \text { Pchr }}$. Cyp $4 f 18+/-$ heterozygous mice were maintained at the Massachusetts General Hospital and mated to generate Cyp4f18 -/- homozygous knockouts and Cyp4f18 +/+ wild-type littermates for experiments. Genotyping assays are as previously described [22]. Breeding and experimentation of mice were performed in accordance with the guidelines of the Massachusetts General Hospital/Partners Committee on Research Animal Care. Mice of 6-12 weeks of age were used for experiments.

2.2. Isolation of Bone Marrow Neutrophils. Mouse bone marrow cells were isolated from femurs and tibias by perfusion with phosphate buffered saline (PBS). The cells were filtered through a $40 \mu \mathrm{m}$ cell strainer, washed in PBS, and layered on top of a discontinuous two-layer gradient of Histopaque 1077/1119 (Sigma). After centrifugation at $700 \times \mathrm{g}$ for $30 \mathrm{~min}$ at RT, neutrophils were separated from other cells including erythrocytes and recovered at the interface of the 1077 and 1119 fractions. Purity of the isolated polymorphonuclear cells was confirmed $(>90 \%)$ by staining nuclei with DAPI and examination under a Nikon Eclipse Ti microscope with confocal imaging. Viability of the cells $(>95 \%)$ was assessed by trypan blue exclusion.

2.3. In Vitro Chemotaxis Assay. Bone marrow neutrophils were isolated as described above and resuspended in migration medium (RPMI $+0.5 \%$ FBS) to a concentration of 3 $\times 10^{6}$ cells $/ \mathrm{mL}$. Chemotaxis was performed using a 12 -well plate with Transwell $12 \mathrm{~mm}$ polycarbonate membrane inserts of $3.0 \mu \mathrm{M}$ pore size (Corning 3402). The cells were placed in the insert $\left(0.5 \mathrm{~mL}, 1.5 \times 10^{6}\right.$ cells per insert), and $1.5 \mathrm{~mL}$ of migration medium containing different concentrations of chemoattractant was placed in the lower well. Migration medium containing vehicle but no chemoattractant was used as a control to measure background chemotaxis, and chemoattractant was added to both the insert and the lower well as a control for chemokinesis. The 12-well plates were incubated for 3 hours at $37^{\circ} \mathrm{C}$ in a $5 \% \mathrm{CO}_{2}$ incubator. The medium in the lower well was transferred to a $12 \times 75 \mathrm{~mm}$ sterile culture tube (BD Falcon), and the well was washed with PBS. The tubes were then centrifuged for $5 \mathrm{~min}$ at $200 \times \mathrm{g}$, and the cell pellet was resuspended in $0.1 \mathrm{~mL}$ migration medium. The total number of cells was determined using a hemocytometer. To calculate the chemotactic index, the number of cells migrated in response to chemoattractant was divided by the number of spontaneously migrated cells (background).

The chemoattractants tested were $\mathrm{LTB}_{4}$ (Cayman), mouse complement component C5a (R\&D Systems), mouse 
CXCL1/KC (R\&D Systems), and WKYMVdM peptide (Sigma) as an agonist for the mouse formyl peptide receptor. In some experiments, bone marrow neutrophils were incubated with or without inhibitors of eicosanoid synthesis or BLT1 for $30 \mathrm{~min}$ at $37^{\circ} \mathrm{C}$ prior to adding the cells to the 12 -well plate inserts. This included incubations with $0.5 \mu \mathrm{M}$ of the FLAP inhibitor MK 886 (Cayman 10133), $1 \mu \mathrm{M}$ of a cPLA2 $\alpha$ inhibitor (Calbiochem 525143, PubChem CID 9833099), and $10 \mu \mathrm{M}$ of the BLT1 antagonist LY223982 (Cayman 10010024). Each experimental condition was performed in duplicate or triplicate on a single 12-well plate, and each experiment was performed at least 4 times $(n \geq 4)$.

2.4. Flow Cytometry. Bone marrow cell suspensions in PBS $+0.5 \%$ BSA were preincubated with Mouse Fc Block (BD Biosciences) for $5 \mathrm{~min}$ at $4^{\circ} \mathrm{C}\left(0.5 \mu \mathrm{g} / 10^{6}\right.$ cells $\left./ 100 \mu \mathrm{L}\right)$ and then incubated with fluorophore-conjugated anti-mouse monoclonal antibodies for $30 \mathrm{~min}$ at $4^{\circ} \mathrm{C}$ (antibodies diluted to $1 \mu \mathrm{g} / \mathrm{mL}$ ). Anti-CD45-PerCP (clone 30-F11) and antiLy6G-FITC (clone 1A8) were from BD Biosciences. AntiC5aR(CD88)-APC (clone 20/70) was from BioLegend. The cells were fixed in $\mathrm{BD}$ stabilizing fixative (BD Biosciences). Labeled cells were analyzed at the Flow Cytometry Core Facility, Massachusetts General Hospital, using a BD SORP 7 Laser LSRII and FlowJo software, as in previous studies $[19,22]$. The cells were gated on forward versus side scatter, then for CD45 expression, prior to double plot analysis of Ly6G and $\mathrm{C} 5 \mathrm{aR}$ (numbers were assigned to each quadrant to indicate percentage of total CD45+ cells). Bone marrow samples from 5 wild-type mice and 5 Cyp $4 f 18$ knockout mice were analyzed.

2.5. RNA Isolation and Real Time PCR. Total RNA was isolated from cells and tissues using the RNeasy Plus Mini Kit with QIAshredder (Qiagen). Reverse transcription was performed with a High Capacity cDNA Reverse Transcription Kit (Life Technologies, Applied Biosystems). The cDNA was analyzed for target gene expression using TaqMan primer sets and a StepOnePlus real time PCR machine from Applied Biosystems. A standard reaction protocol was followed $\left(50^{\circ} \mathrm{C}\right.$ for $2 \mathrm{~min}, 95^{\circ} \mathrm{C}$ for $10 \mathrm{~min}, 40$ cycles of $95^{\circ} \mathrm{C}$ for $15 \mathrm{sec}$ and $60^{\circ} \mathrm{C}$ for $1 \mathrm{~min}$ ). Relative quantification of gene expression in knockout samples compared to wild-type was performed by the $\Delta \Delta \mathrm{Ct}$ method using mouse GAPDH as endogenous control. Each sample was run in triplicate to determine $\Delta \mathrm{Ct}$ values, $2^{-\Delta \mathrm{Ct}}$ values, or fold-differences in expression $\left(2^{-\Delta \Delta \mathrm{Ct}}\right)$. Values from four experiments were expressed as mean \pm SEM. The TaqMan primer-probe sets were purchased from Life Technologies (Applied Biosystems) as listed in Table 1.

2.6. Dextran Sodium Sulfate (DSS) Colitis. DSS (MP Biomedicals) of average molecular weight $42 \mathrm{kDa}(35-50,000)$ was administered to 8-week-old mice ad libitum at a concentration of $4 \%$ in drinking water for 9 days. Control mice received the same drinking water without DSS $(n=10$ mice in each group). Changes in body weight were calculated every day. A disease activity index (DAI) was determined by assigning a score of $1-4$ for weight loss $(1: 1-5 \%, 2: 5-10 \%, 3: 10-15 \%$,
TABLE 1: Summary of primers.

\begin{tabular}{|c|c|}
\hline \multicolumn{2}{|c|}{$\begin{array}{c}\text { TaqMan primers for real time PCR } \\
\text { (Applied Biosystems/Life Technologies) }\end{array}$} \\
\hline C5ar1 & Mm00500292_s1 \\
\hline Cyp4a10 & Mm01188913_g1 \\
\hline Cyp4a12a & Mm00514494_m1 \\
\hline Cyp4a12b & Mm00655431_gH \\
\hline Cyp4a14 & Mm00484135_ml \\
\hline Сур4a29 & Mm01188902_g1 \\
\hline Сур4a30b & Mm01181463_ml \\
\hline Сур4а31 & Mm03047753_m1 \\
\hline Cyp4b1 & Mm01193710_m1 \\
\hline Cyp4x1 & Mm01181487_m1 \\
\hline Сур4f13 & Mm00504576_ml \\
\hline Сур4f14 & Mm00491623_m1 \\
\hline Сyp4f15 & Mm00506542_m1 \\
\hline Сур4f16 & Mm00775893_ml \\
\hline Сyp4f17 & Mm01345625_m1 \\
\hline Сур4f39 & Mm00624134_m1 \\
\hline Cyp4f40 & Mm01342246_m1 \\
\hline \multicolumn{2}{|c|}{ Custom TaqMan primers } \\
\hline \multicolumn{2}{|l|}{ Сур4f18 } \\
\hline Forward & AGTGGACTTTCCTGGATCCTGTAC \\
\hline Reverse & GGCAGCGCTCCTGGTATTC \\
\hline Probe & ACCTGGCAAGACACC \\
\hline \multicolumn{2}{|l|}{ Cyp4f37 } \\
\hline Forward & TCCCGCCTCAGATGTTTCC \\
\hline Reverse & CCCAAGTGACCCAAAAACCA \\
\hline Probe & TCAGCCTCCTAAAAGA \\
\hline \multicolumn{2}{|l|}{ Mouse blt1 } \\
\hline Forward & CCGACTTGGCTGTGTTGCT \\
\hline Reverse & GTGCCTCGAGCCAGAAAGTG \\
\hline Probe & ACTGCTCCСTTTTTC \\
\hline
\end{tabular}

Sequences are shown in $5^{\prime}$ to $3^{\prime}$ direction.

and 4 : $>15 \%$ ), rectal bleeding (ranging from 1: positive to 4: gross bleeding), stool consistency (ranging from 1: loose stools to 4: diarrhea with fecal material adherent to anal fur), and body posture/lethargy (ranging from 1: mild to 4: severe). The total scores were averaged to give a value between 0 (normal) and 4 (maximum). Mice were sacrificed on day 9 , and colonic tissue samples were collected for further analysis. Myeloperoxidase (MPO) was measured using an ELISA kit from Hycult Biotech (HK210). The assay was performed on tissue samples that had been frozen and stored at $-70^{\circ} \mathrm{C}$. The samples were thawed, weighed, and homogenized in a lysis buffer containing $200 \mathrm{mM} \mathrm{NaCl}, 5 \mathrm{mM}$ EDTA, $10 \mathrm{mM}$ tris, $10 \%$ glycerin, $1 \mathrm{mM}$ PMSF, $1 \mu \mathrm{g} / \mathrm{mL}$ leupeptin, and $28 \mu \mathrm{g} / \mathrm{mL}$ aprotinin, pH $7.4(20 \mu \mathrm{L}$ lysis buffer per mg tissue). The homogenate was transferred to a $1.5 \mathrm{~mL}$ microfuge tube and centrifuged two times at $1500 \times \mathrm{g}$ for $15 \mathrm{~min}$ at $4^{\circ} \mathrm{C}$. Supernatants were snap frozen in liquid nitrogen and stored at $-70^{\circ} \mathrm{C}$. MPO was assayed by ELISA according to the manufacturer's instructions. 
2.7. Statistical Analysis. The data was analyzed using Graphpad Prism version 5 statistical software. The results are expressed as the mean \pm SEM. A $t$-test was used for comparisons of paired data, and multigroup data were analyzed by ANOVA. A $P$ value of less than 0.05 was considered significant.

\section{Results}

3.1. LTB $_{4}$-Dependent Neutrophil Chemotaxis. $\mathrm{LTB}_{4}$-dependent chemotaxis of neutrophils from wild-type and Cyp4f18 knockout C57BL/6 mice was compared using an in vitro assay. A dose-dependent increase in chemotaxis was observed (Figure 1). For wild-type (WT) neutrophils, the chemotactic index increased from $1.27 \pm 0.12$ at $1 \mathrm{nM} \mathrm{LTB}_{4}$ to $2.73 \pm 0.7$ at $10 \mathrm{nM} \mathrm{LTB}_{4}$ and $8.53 \pm 0.64$ at $100 \mathrm{nM} \mathrm{LTB}_{4}$. For Cyp4f18 knockout $(\mathrm{KO})$ neutrophils, the chemotactic index increased from $1.4 \pm 0.1$ at $1 \mathrm{nM} \mathrm{LTB}$ to $3.3 \pm 0.77$ at $10 \mathrm{nM} \mathrm{LTB}_{4}$ and $9.27 \pm 0.77$ at $100 \mathrm{nM} \mathrm{LTB}_{4}$. At each concentration, there was no significant difference between the chemotactic index for wild-type and Cyp4f18 knockout neutrophils $(n=10$, $P>0.05)$.

3.2. C5a-Dependent Neutrophil Chemotaxis. The complement component $\mathrm{C} 5 \mathrm{a}$ was originally used as a control in these experiments, because $\mathrm{C} 5 \mathrm{a}$-dependent chemotaxis was not expected to be affected by loss of Cyp4f18. Surprisingly, significant differences in chemotaxis were observed when comparing wild-type and knockout neutrophils (Figure 2). For wild-type neutrophils, the chemotactic index increased from $1.7 \pm 0.46$ at $1 \mathrm{ng} / \mathrm{mL}$ C5a to $4.79 \pm 0.48$ at $10 \mathrm{ng} / \mathrm{mL}$ $\mathrm{C} 5 \mathrm{a}$ and $9.2 \pm 0.79$ at $100 \mathrm{ng} / \mathrm{mL}$ C5a. For Cyp $4 f 18$ knockout (KO) neutrophils, the chemotactic index increased from $2.2 \pm 0.38$ at $1 \mathrm{ng} / \mathrm{mL}$ C5a to $11.2 \pm 1.1$ at $10 \mathrm{ng} / \mathrm{mL}$ C5a and $17.3 \pm 1.7$ at $100 \mathrm{ng} / \mathrm{mL} \mathrm{C} 5 \mathrm{a}$. There was a significant difference between the chemotactic index for wild-type and Cyp4f18 knockout neutrophils at $10 \mathrm{ng} / \mathrm{mL}$ C5a $(P<0.01)$ and $100 \mathrm{ng} / \mathrm{mL} \mathrm{C5a}(P<0.05)$, but not at $1 \mathrm{ng} / \mathrm{mL} \mathrm{C5a}$ (Figure 2(a)). Overall, the relative difference in chemotactic index for knockout compared to wild-type was 2.3-fold at $10 \mathrm{ng} / \mathrm{mL}$ C5a and 1.9-fold at $100 \mathrm{ng} / \mathrm{mL} \mathrm{C5a} \mathrm{(Figure} \mathrm{2(b)).} \mathrm{No}$ significant differences between Cyp4f18 knockout and wildtype neutrophil chemotaxis were observed when CXCL1/KC or WKYMVdM peptide was used as chemoattractant (data not shown).

Previous studies demonstrated that $\mathrm{LTB}_{4}$ is a signal relay molecule during neutrophil chemotaxis: $\mathrm{LTB}_{4}$ synthesis and secretion are induced by primary chemoattractants such as C5a, and this amplifies neutrophil migration $[20,26]$. The amplification is reduced by MK 886 [20], a FLAP inhibitor that is known to block 5-lipoxygenase activation and leukotriene synthesis [27]. As expected, we observed a decrease in C5a-dependent chemotaxis in neutrophils treated with MK 886 (Figure 2(a)), but the decrease was equivalent in wild-type and Cyp4f18 knockout neutrophils (0.45-0.56fold), such that the relative difference in chemotactic index remained unchanged: 2.21-fold higher in Cyp4f18 knockout neutrophils compared to wild-type at $10 \mathrm{ng} / \mathrm{mL} \mathrm{C} 5 \mathrm{a}$ and 1.92 -fold higher at $100 \mathrm{ng} / \mathrm{mL}$ C5a (Figure 2(b)). Similar

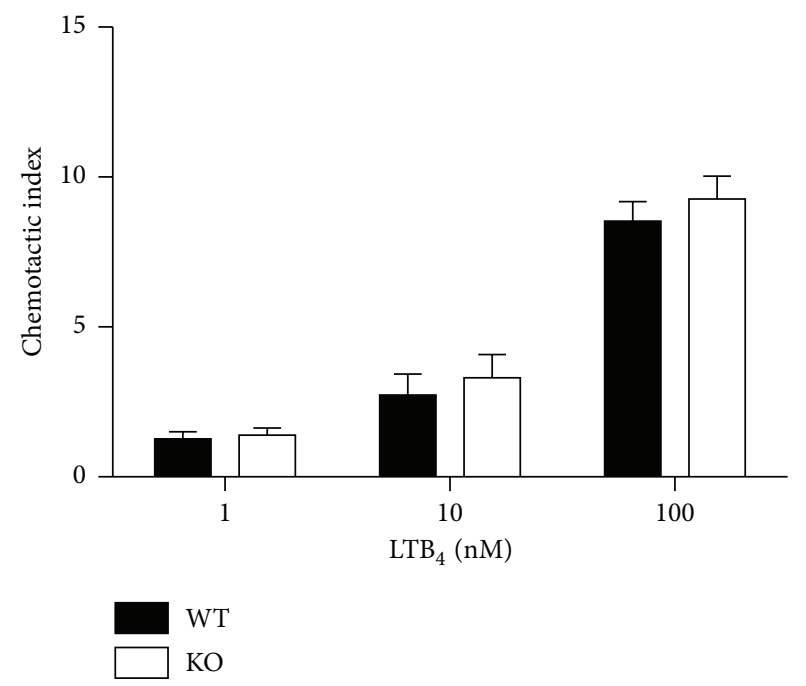

FIGURE 1: Cyp4f18 knockout neutrophils show no change in $\mathrm{LTB}_{4}{ }^{-}$ dependent chemotaxis compared to wild-type. Chemotaxis of bone marrow neutrophils from wild-type (WT) and Cyp4f18 knockout (KO) mice was measured using $\mathrm{LTB}_{4}$ as a chemoattractant. The chemotactic index represents the number of cells migrated in response to $\mathrm{LTB}_{4}$ divided by background (error bars represent SEM, $n=10)$.

results were obtained when neutrophils were treated with a cPLA $2 \alpha$ inhibitor: there was an equivalent decrease in C5adependent chemotaxis in wild-type and Cyp4f18 knockout neutrophils of $0.3-0.37$-fold (Figure 2(a)), and the relative difference in chemotactic index remained unchanged: 2.3fold higher in Cyp4f18 knockout neutrophils at $10 \mathrm{ng} / \mathrm{mL}$ C5a and 1.75 -fold higher at $100 \mathrm{ng} / \mathrm{mL}$ C5a (Figure 2(b)). The cPLA $2 \alpha$ inhibitor is less specific than the FLAP inhibitor: it blocks eicosanoid production by preventing release of arachidonic acid from membrane phospholipids [28] and therefore inhibits synthesis of a wide range of lipid mediators in addition to leukotrienes. Overall, the data show that loss of CYP4F18 results in increased neutrophil chemotaxis to $\mathrm{C} 5 \mathrm{a}$ and suggest that this is independent of $\mathrm{LTB}_{4}$ and other eicosanoids.

LY223982 is a synthetic BLT1 ( $\mathrm{LTB}_{4}$ receptor) antagonist that has been used to study neutrophil function [29]. We incubated neutrophils with LY223982 prior to chemotaxis assays using $10 \mathrm{ng} / \mathrm{mL}$ C5a. This resulted in a 1.7-fold increase in C5a-dependent chemotaxis in wild-type neutrophils and a 2-fold increase in Cyp4f18 knockout neutrophils, compared to cells that were not treated with LY223982 (Figure 2(a)). There is previous evidence for cross-desensitization between neutrophil chemoattractant receptors [30], and this might account for our data: less cross-desensitization of the C5a receptor following inhibition of BLT1 could result in an increased chemotactic response to C5a. However this does not account for the differences between Cyp4f18 knockout and wild-type neutrophils, because the relative difference in chemotactic index remained undiminished following treatment with LY223982: 2.8-fold higher in Cyp4f18 knockout neutrophils compared to wild-type (Figure 2(b)). 


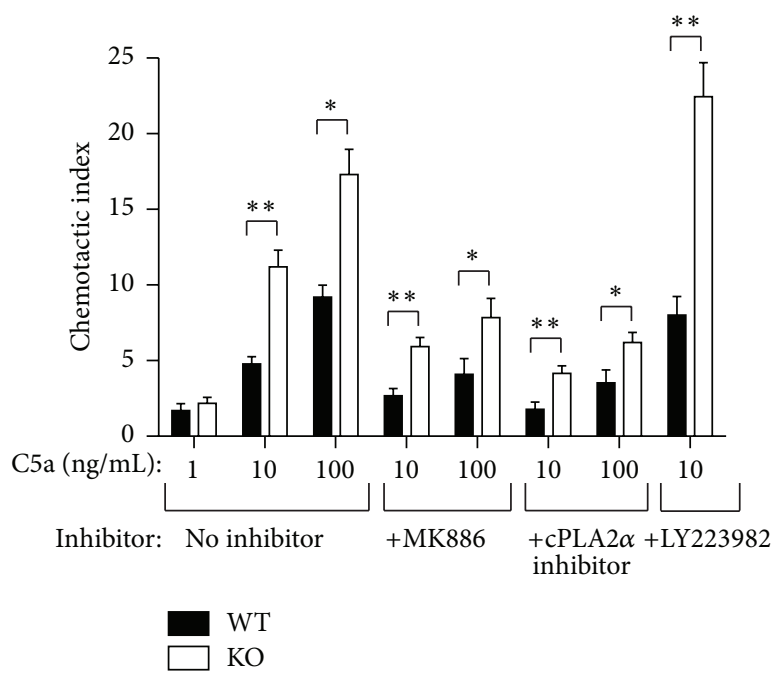

(a)

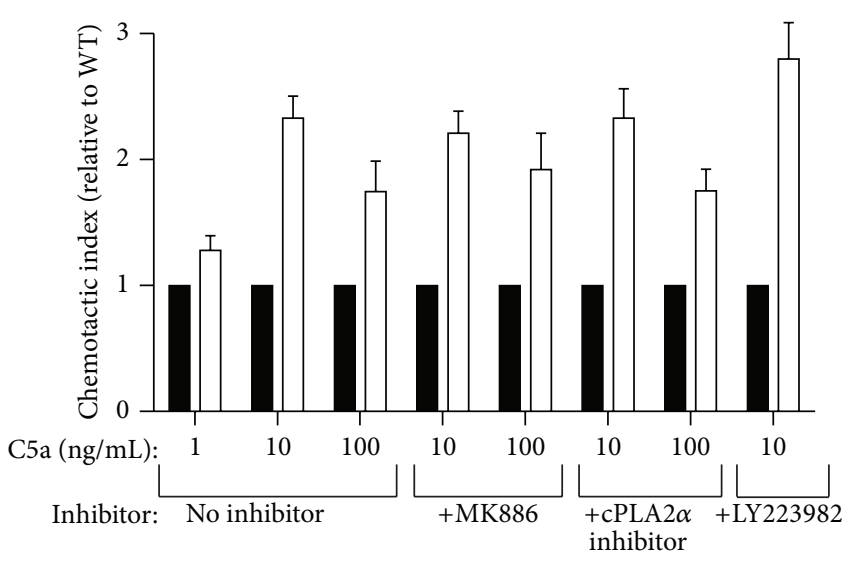

WT

(b)

FIGURE 2: Cyp4f18 knockout neutrophils show increased C5a-dependent chemotaxis compared to wild-type. Chemotaxis of bone marrow neutrophils from wild-type (WT) and Cyp4f18 knockout (KO) mice was measured using C5a as a chemoattractant. Prior to chemotaxis, the neutrophils were incubated with or without the FLAP inhibitor MK $886(0.5 \mu \mathrm{M})$, a cPLA2 $\alpha$ inhibitor (CID 9833099, $1 \mu \mathrm{M})$, or a BLT1 antagonist (LY223982, $10 \mu \mathrm{M}$ ). (a) Chemotactic index represents the number of cells migrated in response to C5a divided by background (error bars represent SEM, $n=5,{ }^{*} P<0.05,{ }^{* *} P<0.01$ ). (b) Schematic plot for the relative difference in chemotactic index in $C y p 4 f 18$ knockout neutrophils compared to wild-type for each experimental condition.

3.3. Comparison of Gene Expression in Cyp4f18 Knockout and Wild-Type Neutrophils. We have previously used multicolor flow cytometry analysis of cells from mouse bone marrow and other tissues to investigate protein expression in different cell lineages $[19,22]$. Ly6G is a component of the myeloid marker Gr-1 (ly6G + Ly6C) that is preferentially expressed in neutrophils, and fluorophore-conjugated monoclonal antibodies to Ly6G are useful to identify neutrophils in flow cytometry studies [22]. Using this approach, mouse bone marrow cells were stained with anti-Ly6G-FITC and anti-C5aR-APC, and analysis of double plots shows an equivalent level of C5a receptor (C5aR) expression in neutrophils from Cyp4f18 knockout and wild-type mice (Figure 3(a)). Real time PCR analysis of isolated bone marrow neutrophils (Figure 3(b)) determined that there is no significant difference in mRNA expression of C5aR or BLT1 in Cyp4f18 knockout neutrophils compared to wild-type $(n=4, P>0.05)$. A plot of $2^{-\Delta \mathrm{Ct}}$ values shows that $\mathrm{C} 5 \mathrm{aR}$ is expressed at approximately 10 fold higher levels than BLT1 in the cells (Figure 3(b)). The values for relative expression $\left(2^{-\Delta \Delta \mathrm{Ct}}\right)$ of $\mathrm{C} 5 \mathrm{aR}$ in knockout neutrophils compared to wild-type ranged from 0.92 to 1.05 .

A real time PCR assay designed to detect exons 8 and 9 of Cyp $4 \mathrm{f} 18$ was used to confirm loss of expression of these exons in knockout mice, as previously described [22]. We routinely performed real time PCR analysis of isolated bone marrow neutrophils to determine if changes in expression of other Cyp genes might account for differences in the Cyp4f18 knockout. We have previously shown that Cyp4f18 is the predominant Cyp4f subfamily member in bone marrow neutrophils and that Cyp4f13 and Cyp4f16 are detected at lower levels [22]. In this study, we extended the analysis to include all Cyp4 family members in mouse (Figure 3(c)).
No other Cyp4 transcripts were detected in wild-type or knockout neutrophils. Importantly, there were no changes in Cyp4 expression in knockout neutrophils that might compensate for the loss of Cyp4f18 or lead to differences in activity of the cells.

3.4. Mouse Model of DSS Colitis. A mouse model of DSS colitis was used to investigate the consequences of increased C5a-dependent chemotaxis in vivo (Figure 4). Inhibition of C5a activity has been shown to reduce disease pathology in this model in C57BL/6 mice [31]. Continuous administration of $4 \%$ DSS in drinking water to 8 -week-old mice resulted in a rapid decline in body weight from $98.7 \pm 1.35 \%$ of initial weight on day 6 to $78.5 \pm 3.8 \%$ of initial weight on day 9 in wild-type mice. There was a corresponding increase in disease activity index $($ maximum $=4)$ from $1.3 \pm 0.29$ on day 6 to $3.2 \pm 0.24$ on day 9. There were no significant differences in the values for loss of weight or increase in disease activity in Cyp4f18 knockout mice $(n=10, P>0.05)$. MPO, an enzyme produced mainly by neutrophils, was measured in colonic tissue to quantify inflammatory cell infiltration (Figure 5). On day 9 , the MPO level was $57 \pm 9.0 \mathrm{ng} / \mathrm{mg}$ tissue in wildtype mice and $55 \pm 7.1 \mathrm{ng} / \mathrm{mg}$ tissue in Cyp4f18 knockout mice $(n=5, P>0.05)$. Based on the similarity of these indicators, we did not proceed with further histological analysis of colon tissue.

\section{Discussion}

We previously generated Cyp4f18 knockout mice [22], and predicted that the mice would exhibit altered $\mathrm{LTB}_{4}{ }^{-}$ dependent inflammation based on the ability of the CYP4F18 

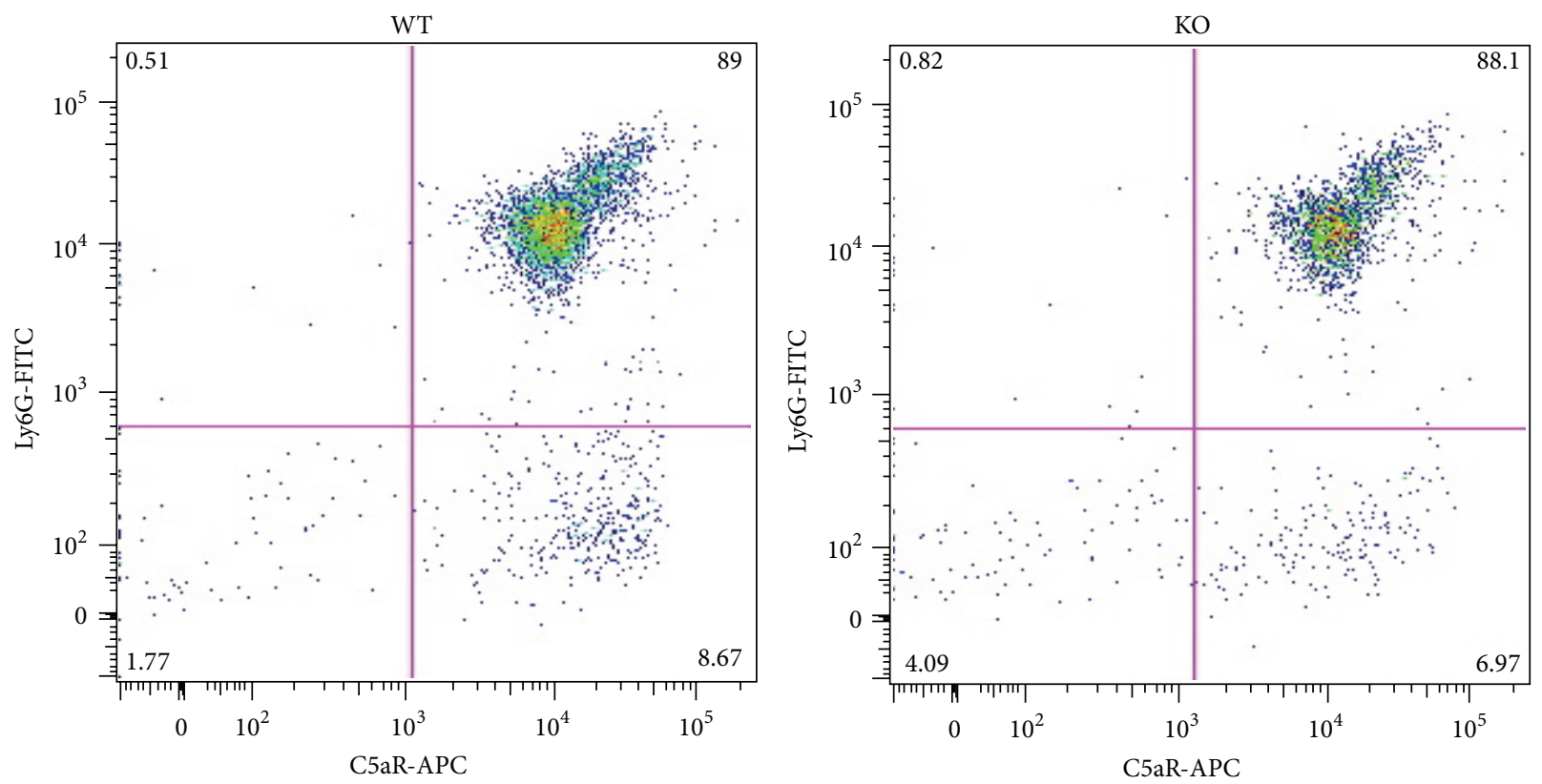

(a)

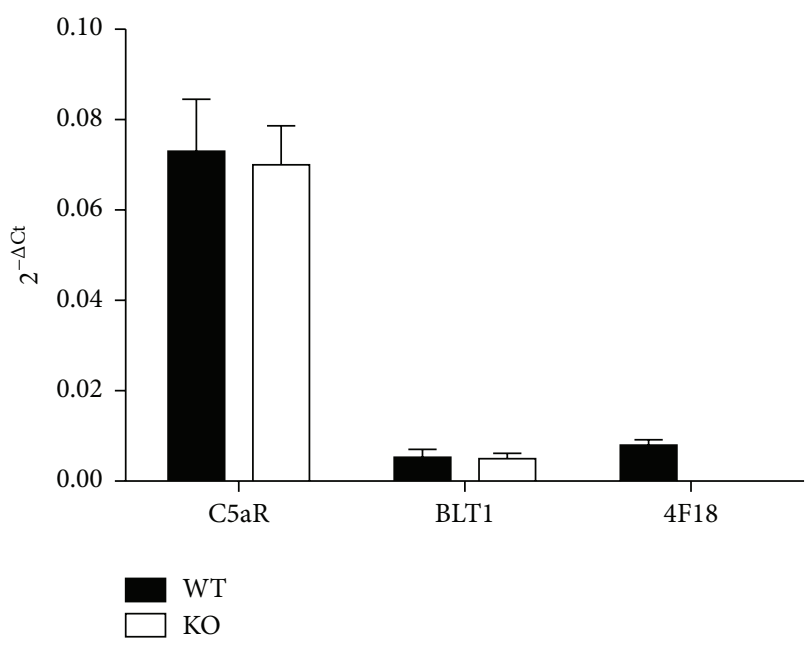

(b)

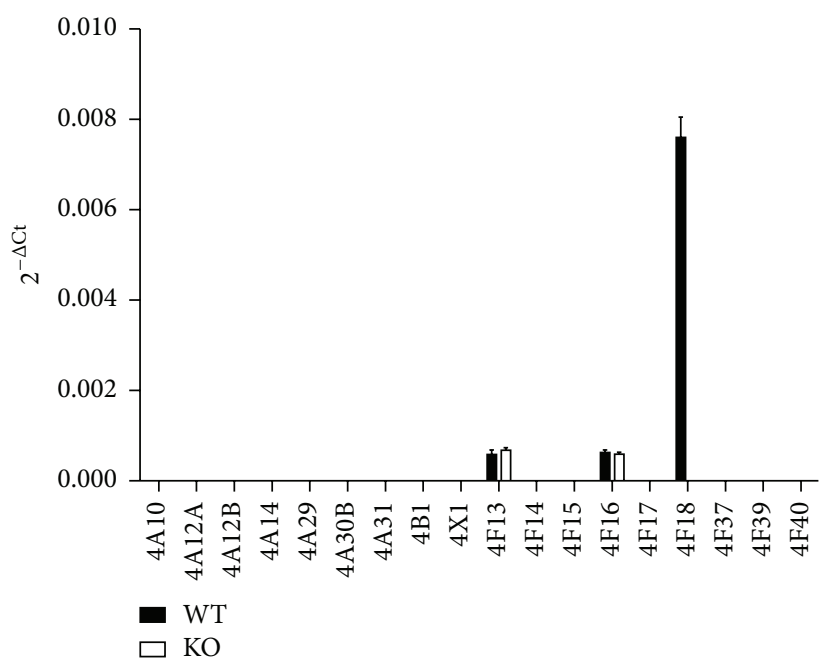

(c)

Figure 3: Gene expression in wild-type and Cyp4f18 knockout neutrophils. Flow cytometry analysis of bone marrow cells from wild-type (WT) and Cyp4f18 knockout (KO) mice using antibodies to Ly6G (neutrophil marker) and C5aR; representative double plots from individual mice are shown (a). Reverse transcription and real time PCR analysis of C5aR mRNA expression (b) and CYP4 mRNA expression (c), in isolated bone marrow neutrophils. $\Delta \mathrm{Ct}$ values were determined for each transcript using GAPDH as endogenous control, and $2^{-\Delta \mathrm{Ct}}$ values were plotted for WT and KO samples $(n=4)$. Relative quantitation $\left(2^{-\Delta \Delta \mathrm{Ct}}\right)$ determined that there was no significant change in expression of any of the transcripts tested in knockout samples compared to wild-type, except for the loss of CYP4F18.

enzyme to metabolize $\mathrm{LTB}_{4}$ in neutrophils. However, there were no significant differences in inflammation and injury in a mouse model of renal IRI compared to wild-type [22], although inhibition of $\mathrm{LTB}_{4}$ synthesis does ameliorate pathology in this model [23]. The results of an in vitro chemotaxis assay are consistent with these previous observations in vivo. $\mathrm{LTB}_{4}$ stimulated chemotaxis of neutrophils in a dosedependent manner, but there were no significant differences in the response of Cyp4f18 knockout and wild-type cells (Figure 1). In the renal IRI model, we measured infiltration of neutrophils into kidney tissue by traditional histological approaches and flow cytometry and demonstrated a comparable time course and magnitude of infiltration in Cyp4f18 knockout and wild-type mice [22]. However, the loss of CYP4F18 might be compensated by other CYP4Fs in the complex tissue physiology of inflammation. The in vitro assay reported here confirms that the similarity between wild-type and knockout is inherent to neutrophils.

There are a number of possible explanations for the unaltered chemotactic response to $\mathrm{LTB}_{4}$ in Cyp 4 f18 knockout 

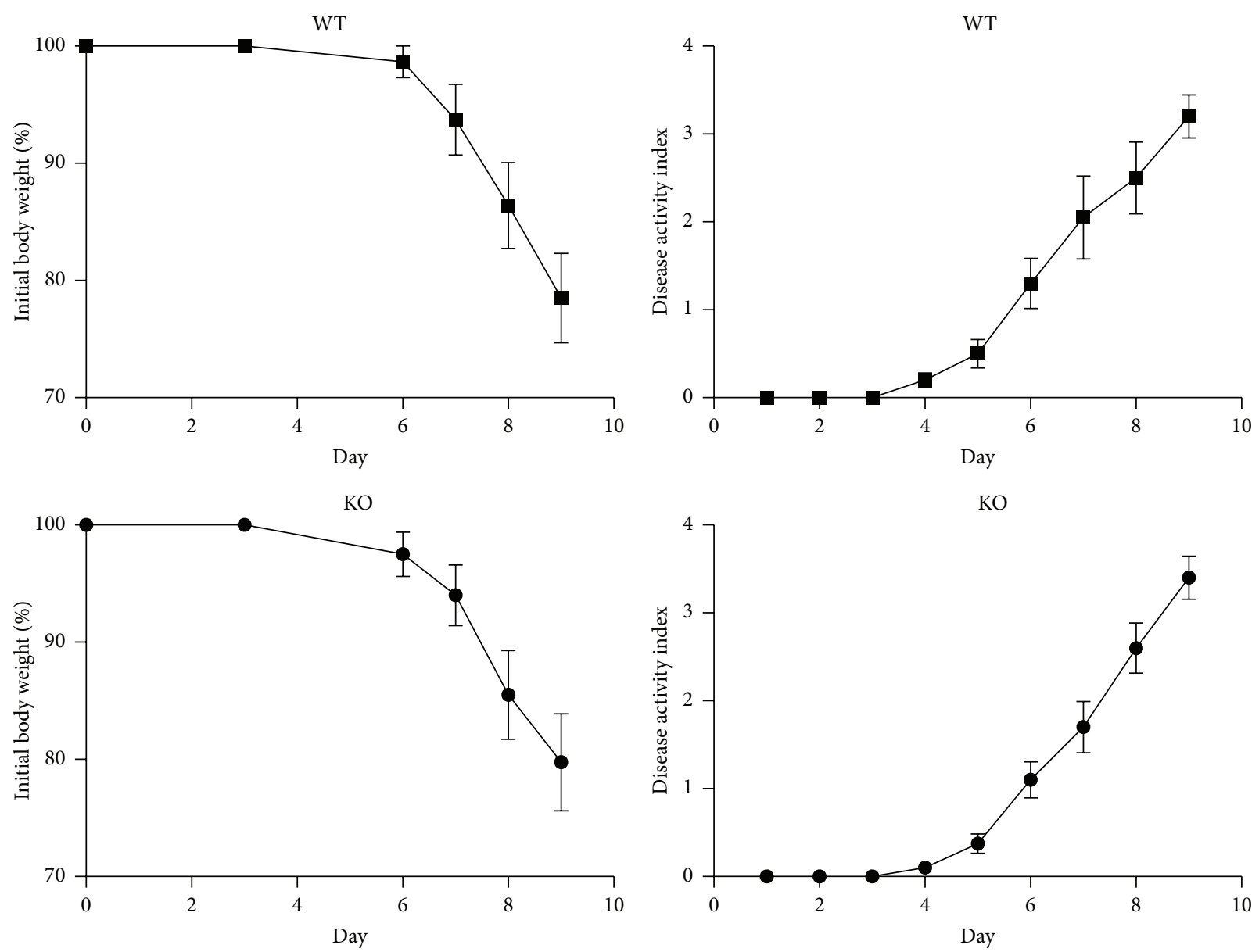

(a)

(b)

FIGURE 4: Mouse model of DSS colitis. Wild-type (WT) and Cyp4f18 knockout (KO) mice were treated with $4 \%$ DSS in drinking water for 9 days, and the change in body weight (a) or disease activity index (b) was measured each day. There were no significant differences between WT and KO mice (data shows mean values \pm SEM, $n=10, P>0.05$ ).

neutrophils. CYP4F18 converts $\mathrm{LTB}_{4}$ to 19 -hydroxy $\mathrm{LTB}_{4}$, and to a lesser extent 18 -hydroxy $\mathrm{LTB}_{4}$, in mouse neutrophils, not 20-hydroxy $\mathrm{LTB}_{4}$ as seen in humans. These products were not detected in Cyp4f18 knockout neutrophils [22], but it is not known whether $\omega-1$ and $\omega$-2 hydroxylation of $\mathrm{LTB}_{4}$ represents an efficient inactivation pathway. These studies underscore the importance of accurately identifying the metabolites produced by CYP4Fs. It is sometimes difficult to distinguish the $\omega, \omega-1$, and $\omega-2$ metabolites of CYP hydroxylases, but this can have physiological and pharmacological importance. For example, 19-HETE is produced by a number of CYPs and is an antagonist of 20-HETE [32]. We have provided experimental details for the identification of 18- and 19-hydroxy $\mathrm{LTB}_{4}$ $[21,22]$, but further studies are needed to clarify the roles of these metabolites. Another possibility is that CYP4F18 is redundant for $\mathrm{LTB}_{4}$ metabolism, because mouse neutrophils have an alternative pathway for $\mathrm{LTB}_{4}$ inactivation involving a 12-hydroxydehydrogenase that is not affected in Cyp4fi8 knockouts [22]. We speculated that CYP4F18 might have an alternative function in mouse neutrophils and that its homologue evolved to be the dominant $\mathrm{LTB}_{4}$-metabolizing enzyme in humans coincident with its ability to generate 20-hydroxy $\mathrm{LTB}_{4}$. This would predict that Cyp4f18 knockout neutrophils exhibit $\mathrm{LTB}_{4}$-independent phenotypes.

Unexpectedly, a difference in response to complement component $\mathrm{C} 5 \mathrm{a}$ was identified using the in vitro chemotaxis assay. Compared to wild-type neutrophils, Cyp4f18 knockout neutrophils show an increase in chemotaxis of 2.3-fold at $10 \mathrm{ng} / \mathrm{mL} \mathrm{C5a}$ and 1.9 -fold at $100 \mathrm{ng} / \mathrm{mL}$ C5a (Figure 2). Primary chemoattractants such as C5a stimulate $\mathrm{LTB}_{4}$ synthesis and secretion, which amplifies neutrophil chemotaxis [20, 26]. Therefore, it is possible that increased C5a-dependent chemotaxis in Cyp4f18 knockout neutrophils might be caused by increased levels of $\mathrm{LTB}_{4}$ or other eicosanoids arising from endogenous synthesis. We used two different inhibitors to investigate this possibility: a FLAP inhibitor (MK 886) that blocks activation of 5-lipoxygenase and a cPLA2 $\alpha$ inhibitor that blocks eicosanoid production by preventing release of arachidonic acid from membrane phospholipids. These inhibitors reduced C5a-dependent chemotaxis to an equivalent degree in both wild-type and Cyp4f18 knockout neutrophils, such that the relative difference in knockout 


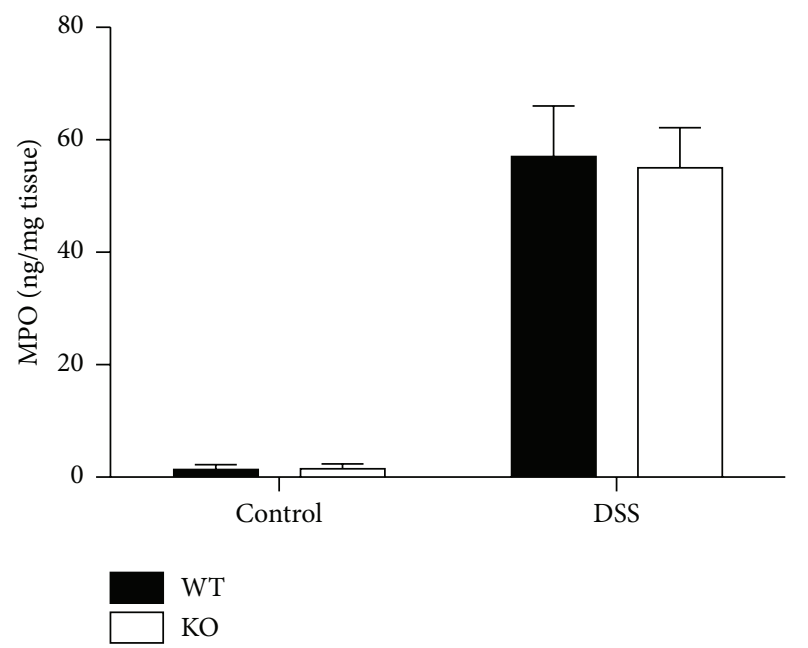

FIgURE 5: Myeloperoxidase (MPO) levels in colonic tissue in DSS colitis. MPO was measured by ELISA in colonic tissue homogenates from wild-type (WT) and Cyp4f18 knockout (KO) mice treated for 9 days with $4 \%$ DSS in drinking water (error bars represent SEM, $n=5$ ). Control mice received drinking water without DSS.

cells compared to wild-type remained unchanged (Figure 2). A BLT1 antagonist increased C5a-dependent chemotaxis in both wild-type and Cyp4f18 knockout neutrophils (Figure 2), possibly by blocking cross-desensitization between the chemoattractant receptors [30]. The relative difference in chemotaxis was undiminished following treatment with the BLT1 antagonist: 2.8-fold higher in Cyp4f18 knockout neutrophils compared to wild-type (Figure 2). Overall, the data suggest that the increase in $\mathrm{C} 5 \mathrm{a}$-dependent chemotaxis in knockout neutrophils is unrelated to $\mathrm{LTB}_{4}$, other eicosanoids, or receptor cross-desensitization. An alternative possibility is that CYP4F18 metabolizes a novel lipid substrate involved in the downstream signaling pathways and relay systems that mediate C5a activity (C5a is a polypeptide and therefore not a CYP substrate).

CYPs typically have broad and overlapping substrate specificity, and redundancy of function is a consistent problem with CYP knockout studies. It is often difficult to observe a phenotype for deletion of one CYP in vivo, because of the effects of multiple related CYPs in complex tissue environments. There are advantages to studying Cyp4f18 knockout neutrophils in vitro, because CYP4F18 is the only CYP4 transcript expressed at high levels in these cells (Figure 3). Another problem with CYP knockout studies is that deletion of one CYP sometimes leads to up- or downregulation of a different CYP that generates an observed phenotype. For example, knockout of Cyp4a14 led to male-specific hypertension that was caused by upregulation of Cyp4a12 [33]. We compared expression of all members of the CYP4 family in wild-type and Cyp4f18 knockout neutrophils and detected no differences other than loss of Cyp4f18 in the knockout (Figure 3).

We used a mouse model of DSS colitis for a preliminary investigation of the consequences of altered C5a chemotaxis in vivo. A C5a receptor antagonist ameliorates pathology in this model [31], and genetic association studies link variants of the CYP4F2 and CYP4F3 genes with celiac disease in humans [9]. Mice were treated continuously with 4\% DSS for 9 days, but the profile of weight loss, disease activity, and colonic tissue MPO was not significantly different in wild-type and Cyp4f18 knockout mice (Figures 4 and 5). Selection and design of future in vivo strategies will benefit from more in vitro information about Cyp4f18 knockout neutrophils. A comparison of lipid metabolism in wild-type and knockout neutrophils will help to determine if novel CYP4F18 substrates are relevant to C5a chemotaxis and might point to other activities affected by loss of CYP4F18.

\section{Conclusions}

CYP4F enzymes have the ability to catalyze oxidation of a diverse range of lipid substrates related to inflammation. Therefore, these enzymes are emerging as potentially prominent players in immune regulation. A significant challenge is to identify physiologically relevant substrates among multiple possibilities and to assign functions to individual CYPs. Knockout studies are problematic because of the ability of related CYPs to compensate for function or to change expression and lead to phenotypes that are unrelated to the deleted CYP. Neutrophils provide a useful tool for our studies of Cyp4f18 knockout mice: CYP4F18 is the only CYP4 enzyme expressed at high levels in these cells, and other CYP4 enzymes do not change expression in Cyp4f18 knockout neutrophils. In this report we demonstrate that there is no difference in $\mathrm{LTB}_{4}$-dependent chemotaxis of mouse neutrophils that lack CYP4F18, despite the high activity of CYP4F18 for $\mathrm{LTB}_{4}$ as a substrate. This is significant, because many studies assume that CYP4Fs regulate $\mathrm{LTB}_{4}$ function based on known activity as $\mathrm{LTB}_{4}$ hydroxylases. We identified an unexpected role for CYP4F18 in regulating C5a-dependent neutrophil chemotaxis, and this was independent of $\mathrm{LTB}_{4}$. Further studies of Cyp4f18 knockout neutrophils in vitro will inform the design of in vivo strategies to investigate immune regulation.

\section{Conflict of Interests}

The authors declare that there is no conflict of interests regarding the publication of this paper.

\section{Acknowledgments}

This project was supported by National Institutes of Health Grant R01DK074821 (to Peter Christmas) and a grant from the College of Science and Technology, Radford University.

\section{References}

[1] A. Kalsotra and H. W. Strobel, "Cytochrome P450 4F subfamily: at the crossroads of eicosanoid and drug metabolism," Pharmacology \& Therapeutics, vol. 112, no. 3, pp. 589-611, 2006.

[2] N. Flamand, P. Mancuso, C. H. C. Serezani, and T. G. Brock, "Leukotrienes: mediators that have been typecast as villains," 
Cellular and Molecular Life Sciences, vol. 64, no. 19-20, pp. 26572670, 2007.

[3] J. Z. Haeggström and C. D. Funk, "Lipoxygenase and leukotriene pathways: biochemistry, biology, and roles in disease," Chemical Reviews, vol. 111, no. 10, pp. 5866-5896, 2011.

[4] N. Sehgal, V. Agarwal, R. K. Valli et al., "Cytochrome P4504f, a potential therapeutic target limiting neuroinflammation," Biochemical Pharmacology, vol. 82, no. 1, pp. 53-64, 2011.

[5] A. Kalsotra, L. Du, Y. Wang et al., "Inflammation resolved by retinoid $\mathrm{X}$ receptor-mediated inactivation of leukotriene signaling pathways," The FASEB Journal, vol. 22, no. 2, pp. 538547, 2008.

[6] L. Du, H. Yin, J. D. Morrow, H. W. Strobel, and D. S. Keeney, "20Hydroxylation is the CYP-dependent and retinoid-inducible leukotriene B4 inactivation pathway in human and mouse skin cells," Archives of Biochemistry and Biophysics, vol. 484, no. 1, pp. 80-86, 2009.

[7] A. Ikehata, N. Hiwatashi, Y. Kinouchi, K. Ito, H. Yamazaki, and T. Toyota, "Leukotriene $\mathrm{B}_{4}$ omega-hydroxylase activity in polymorphonuclear leukocytes from patients with inflammatory bowel disease," Prostaglandins, Leukotrienes and Essential Fatty Acids, vol. 49, no. 1, pp. 489-494, 1993.

[8] A. Ikehata, N. Hiwatashi, Y. Kinouchi, H. Yamazaki, K. Ito, and $\mathrm{T}$. Toyota, "Altered leukotriene $\mathrm{B}_{4}$ metabolism in colonic mucosa with inflammatory bowel disease," Scandinavian Journal of Gastroenterology, vol. 30, no. 1, pp. 44-49, 1995.

[9] C. R. Curley, A. J. Monsuur, M. C. Wapenaar, J. D. Rioux, and C. Wijmenga, "A functional candidate screen for coeliac disease genes," European Journal of Human Genetics, vol. 14, no. 11, pp. 1215-1222, 2006.

[10] I. Costea, D. R. Mack, D. Israel et al., "Genes involved in the metabolism of poly-unsaturated fatty-acids (PUFA) and risk for Crohn's disease in children \& young adults," PLoS ONE, vol. 5, no. 12, Article ID e15672, 2010.

[11] R. C. Murphy and M. A. Gijón, "Biosynthesis and metabolism of leukotrienes," Biochemical Journal, vol. 405, no. 3, pp. 379-395, 2007.

[12] S. Shak and I. M. Goldstein, "Omega-oxidation is the major pathway for the catabolism of leukotriene $\mathrm{B}_{4}$ in human polymorphonuclear leukocytes," The Journal of Biological Chemistry, vol. 259, no. 16, pp. 10181-10187, 1984.

[13] Y. Kikuta, E. Kusunose, and M. Kusunose, "Prostaglandin and leukotriene $\omega$-hydroxylases," Prostaglandins \& Other Lipid Mediators, vol. 68-69, pp. 345-362, 2002.

[14] R. J. Soberman, T. W. Harper, R. C. Murphy, and K. F. Austen, "Identification and functional characterization of leukotriene B4 20-hydroxylase of human polymorphonucler leukocytes," Proceedings of the National Academy of Sciences of the United States of America, vol. 112, no. 2, pp. 536-541, 1985.

[15] Y. Kikuta, E. Kusunose, K. Endo et al., "A novel form of cytochrome P-450 family 4 in human polymorphonuclear leukocytes. cDNA cloning and expression of leukotriene $\mathrm{B}_{4}$ omega-hydroxylase," The Journal of Biological Chemistry, vol. 268, no. 13, pp. 9376-9380, 1993.

[16] P. Christmas, S. R. Ursino, J. W. Fox, and R. J. Soberman, "Expression of the CYP4F3 gene. Tissue-specific splicing and alternative promoters generate high and low $K_{m}$ forms of leukotriene $\mathrm{B}_{4} \omega$-hydroxylase," The Journal of Biological Chemistry, vol. 274, no. 30, pp. 21191-21199, 1999.

[17] P. Christmas, J. P. Jones, C. J. Patten et al., "Alternative splicing determines the function of CYP4F3 by switching substrate specificity," The Journal of Biological Chemistry, vol. 276, no. 41, pp. 38166-38172, 2001.

[18] Y. Wang, J. Zhao, A. Kalsotra et al., "CYP4Fs expression in rat brain correlates with changes in $\mathrm{LTB}_{4}$ levels after traumatic brain injury," Journal of Neurotrauma, vol. 25, no. 10, pp. 11871194, 2008.

[19] P. Christmas, N. Carlesso, H. Shang et al., "Myeloid expression of cytochrome P450 4F3 is determined by a lineage-specific alternative promoter," The Journal of Biological Chemistry, vol. 278, no. 27, pp. 25133-25142, 2003.

[20] P. V. Afonso, M. Janka-Junttila, Y. J. Lee et al., " $\mathrm{LTB}_{4}$ is a signalrelay molecule during neutrophil chemotaxis," Developmental Cell, vol. 22, no. 5, pp. 1079-1091, 2012.

[21] P. Christmas, K. Tolentino, V. Primo et al., "Cytochrome P$4504 \mathrm{~F} 18$ is the leukotriene $\mathrm{B}_{4} \omega-1 / \omega-2$ hydroxylase in mouse polymorphonuclear leukocytes: identification as the functional orthologue of human polymorphonuclear leukocyte CYP4F3A in the down-regulation of responses to LTB4," The Journal of Biological Chemistry, vol. 281, no. 11, pp. 7189-7196, 2006.

[22] V. Winslow, R. Vaivoda, A. Vasilyev et al., "Altered leukotriene $\mathrm{B}_{4}$ metabolism in CYP4F18-deficient mice does not impact inflammation following renal ischemia," Biochimica et Biophysica Acta, vol. 1841, no. 6, pp. 868-879, 2014.

[23] N. S. A. Patel, S. Cuzzocrea, P. K. Chatterjee et al., "Reduction of renal ischemia-reperfusion injury in 5-lipoxygenase knockout mice and by the 5-lipoxygenase inhibitor zileuton," Molecular Pharmacology, vol. 66, no. 2, pp. 220-227, 2004.

[24] L. Corcos, D. Le Lucas, C. Le Jossic-Corcos et al., "Human cytochrome P450 4F3: structure, functions, and prospects," Drug Metabolism and Drug Interactions, vol. 27, no. 2, pp. 6371, 2012.

[25] P. Christmas, "Role of cytochrome P450s in inflammation," in Cytochrome P450 Function and Pharmacological Roles in Inflammation and Cancer, vol. 74 of Advances in Pharmacology, pp. 163-192, Elsevier, 2015.

[26] D. J. Allendorf, J. Yan, G. D. Ross et al., "C5a-mediated leukotriene $\mathrm{B}_{4}$-amplified neutrophil chemotaxis is essential in tumor immunotherapy facilitated by anti-tumor monoclonal antibody and $\beta$-glucan," Journal of Immunology, vol. 174, no. 11, pp. 7050-7056, 2005.

[27] C. A. Rouzer, A. W. Ford-Hutchinson, H. E. Morton, and J. W. Gillard, "MK886, a potent and specific leukotriene biosynthesis inhibitor blocks and reverses the membrane association of 5lipoxygenase in ionophore-challenged leukocytes," The Journal of Biological Chemistry, vol. 265, no. 3, pp. 1436-1442, 1990.

[28] K. Seno, T. Okuno, K. Nishi et al., "Pyrrolidine inhibitors of human cytosolic phospholipase $\mathrm{A}_{2}$," Journal of Medicinal Chemistry, vol. 43, no. 6, pp. 1041-1044, 2000.

[29] W. T. Jackson, R. J. Boyd, L. L. Froelich, B. E. Mallett, and D. M. Gapinski, "Specific inhibition of leukotriene $\mathrm{B}_{4}$-induced neutrophil activation by LY223982," The Journal of Pharmacology and Experimental Therapeutics, vol. 263, no. 3, pp. 1009-1014, 1992.

[30] E. D. Tomhave, R. M. Richardson, J. R. Didsbury, L. Menard, R. Snyderman, and H. Ali, "Cross-desensitization of receptors for peptide chemoattractants. Characterization of a new form of leukocyte regulation," The Journal of Immunology, vol. 153, no. 7, pp. 3267-3275, 1994.

[31] U. Jain, T. M. Woodruff, and A. Stadnyk, "The C5a receptor antagonist PMX205 ameliorates experimentally induced colitis associated with increased IL-4 and IL-10," British Journal of Pharmacology, vol. 168, no. 2, pp. 488-501, 2013. 
[32] M. Alonso-Galicia, J. R. Falck, K. M. Reddy, and R. J. Roman, "20-HETE agonists and antagonists in the renal circulation," American Journal of Physiology: Renal Physiology, vol. 277, no. 5, pp. F790-F796, 1999.

[33] V. R. Holla, F. Adas, J. D. Imig et al., "Alterations in the regulation of androgen-sensitive Cyp 4a monooxygenases cause hypertension," Proceedings of the National Academy of Sciences of the United States of America, vol. 98, no. 9, pp. 5211-5216, 2001. 


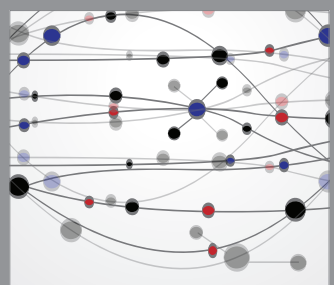

The Scientific World Journal
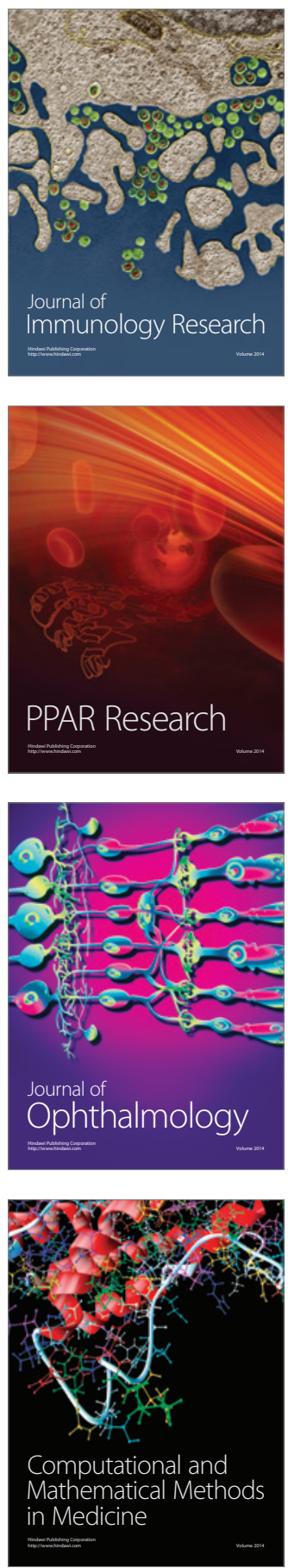

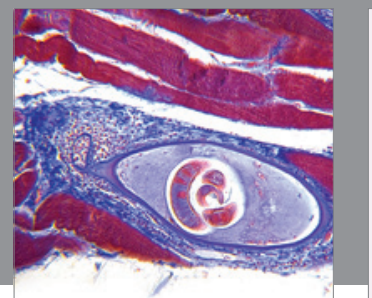

Gastroenterology

Research and Practice
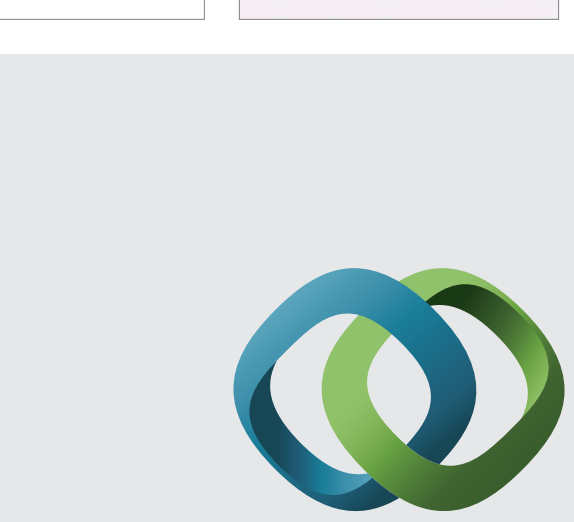

\section{Hindawi}

Submit your manuscripts at

http://www.hindawi.com
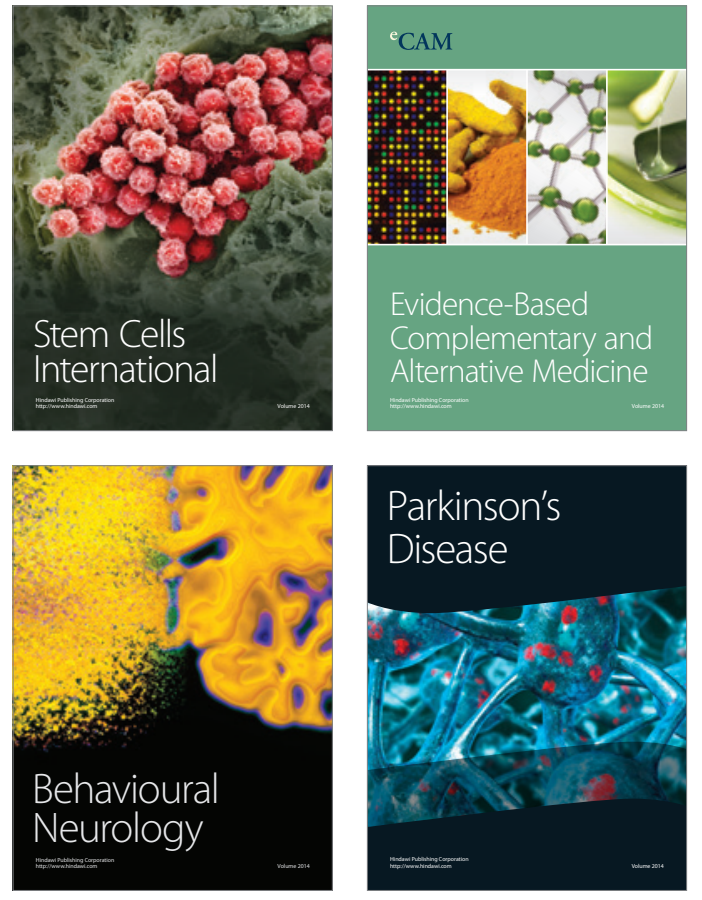
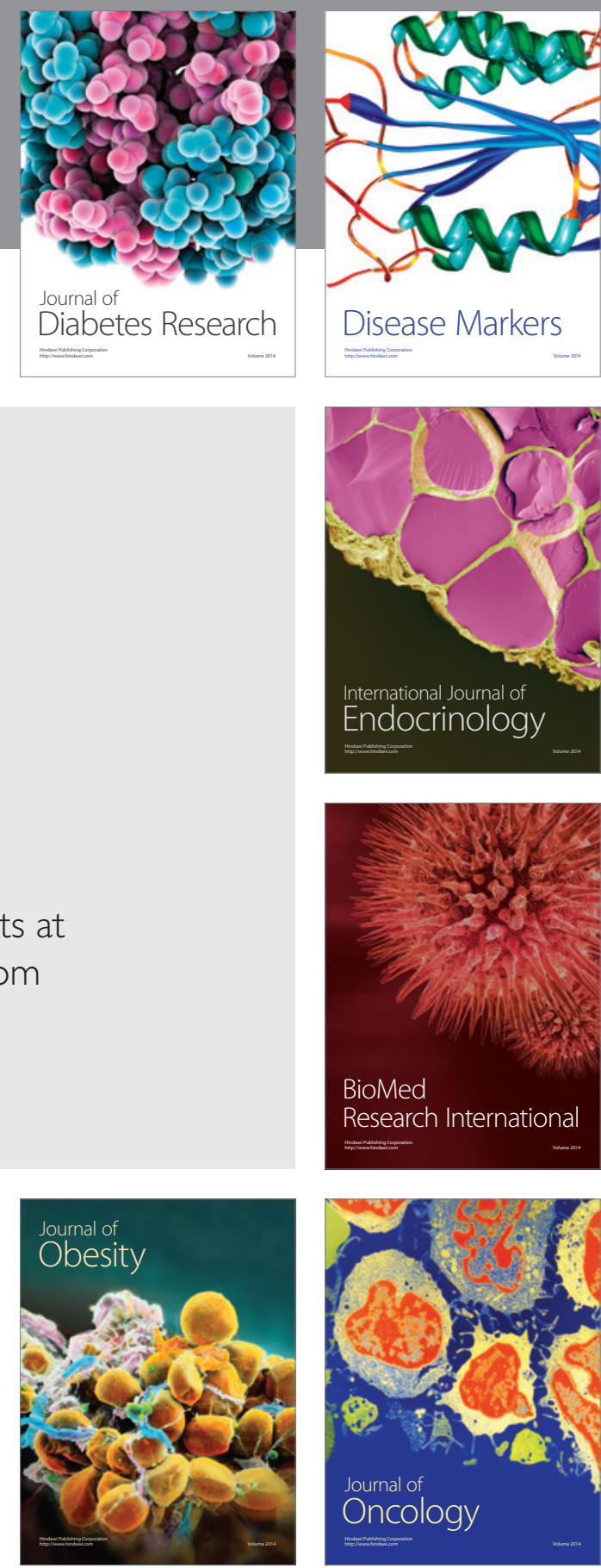

Disease Markers
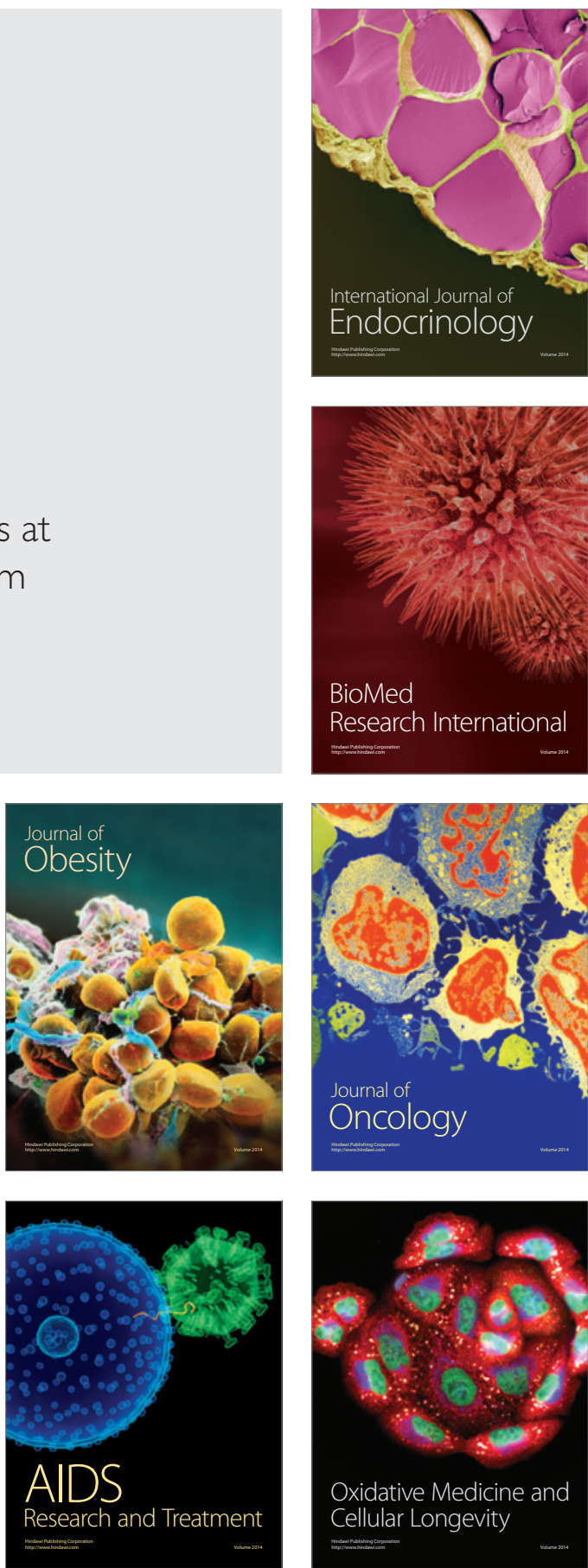